\title{
Análise do balanço radiativo na Avenida Queiroz Filho - São Paulo/SP sob condição de céu claro na estação seca
}

\begin{abstract}
RESUMO: O balanço radiativo e a temperatura das paredes de um "canyon urbano" na Avenida Queiroz Filho na cidade de São Paulo foram observados remotamente com a utilização de radiômetros e termômetros infravermelhos. Estes instrumentos, alocados sobre uma plataforma móvel, fixada em um carro, permitiram caracterizar os padrões radiativos e térmicos, ao longo dessa avenida para diferentes tipos de cobertura e uso da terra, durante as primeiras horas de um período diurno e também durante um período noturno na estação seca. Concomitantemente às observações anteriores, foram executadas medições da temperatura do ar, com o objetivo de se estabelecer um padrão de distribuição espacial da temperatura do ar na via. Pelos resultados alcançados foi possível concluir que a presença de densa cobertura arbórea em uma via urbana pode atenuar drasticamente a variabilidade térmica. Ou seja, enquanto para um setor com pouca ou sem vegetação a taxa de resfriamento radiativo oscila entre 40 e 80 W.m-2, durante o período diurno e o período noturno, respectivamente, para uma região, densamente arborizada, esta mesma taxa de resfriamento permanece aproximadamente constante, em torno de 60 W.m-2, independentemente do ciclo diurno e noturno.
\end{abstract}

\section{Analysis of the radiative balance in Queiroz Filho Avenue - São Paulo, Brazil under clear sky condition during the dry season}

\footnotetext{
ABSTRACT: The radiative balance and the wall temperatures of an urban canyon in the city of São Paulo is remotely observed through the use of radiometers and precision infrared thermometers (IRTs). These instruments are set up on a mobile platform, which moves through the bottom of the canyon. The radiative and thermal patterns are verified, along a traverse, through the different kinds of soil coverage and occupation, during the early hours of a diurnal period and also during a nocturnal period in the dry season. Air temperature measurements are also taken as well as estimates of the spatial temperature distribution, between the atmosphere and urban buildings. The presence of an atmospheric urban temperature gradient is well identified around the area without vegetation coverage, with a maximum magnitude between $6,0^{\circ} \mathrm{C}$ and $12,0^{\circ} \mathrm{C}$. Under the vegetated area it appears that this phenomenon is not pronounced, although a negative net long-wave radiation flux of around $60 \mathrm{~W} . \mathrm{m}-2$ between the bottom analyzed surface and the atmosphere is identified.
}

Antonio Jaschke Machado

Professor Doutor da Universidade Estadual Paulista Júlio de Mesquita Filho - UNESP, Presidente Prudente - São Paulo.

Palavras-chave:

Transeto móvel; Temperatura das paredes; Clima urbano.

Key-words:

Mobile transect; Wall temperature; Urban climate.
Geografia Ensino \& Pesquisa, v. 15, n.1 jan./abr. 2011 


\section{Introdução}

As propostas de planejamento urbano durante estas primeiras décadas do século XXI vêm apresentando uma crescente preocupação com a questão do conforto térmico (OLGYAY, 2008). Porém, os modos de tratamento do problema ainda são insuficientes para que se compreenda adeqüadamente a complexidade dos fenômenos envolvidos no processo de determinação de um estado de conforto.

Este trabalho teve como propósito de apresentar e discutir alguns aspectos físicos do clima urbano, através de um estudo de caso em via urbana, que possam subsidiar a análise do conforto térmico (COSTA et al., 2010; MACHADO e AZEVEDO, 2006).

O caso em estudo teve como área de interesse, um segmento apresentado características geoecológicas e geourbanas típicas de uma metrópole brasileira que compõe um importante eixo de deslocamento na metrópole paulistana, entre o município de Osasco e o centro da cidade de São Paulo, ou seja, a Avenida Queiroz Filho.

Fundamentalmente, busca-se com este estudo, fazer uma reflexão mais aprofundada sobre a análise dos fluxos que compõem o balanço de energia em transetos urbanos, ou seja, mais especificamente monitorar o balanço radiativo, em uma área urbanizada, com características locais marcadamente modificadas pela intervenção humana. Assim o clima urbano deve ser tratado como consequêencia das propriedades térmicas e caloríicas dos materiais utilizados nas suas edificações, pelas modificações da paisagem natural e pelas atividades cotidianas provocadas pelo aumento do fluxo de veículos automotores (BORGES et al, 2008).

\section{Material e método}

\section{Referencial Teórico}

Segundo Oke (1987), a análise de transetos é interessante, sobretudo, porque desvincula a análise, de uma caracterização preponderantemente estática, quando observado certo padrão de distribuição das temperaturas e umidade relativa do ar que preenche a "canopy layer" urbana. Assim sendo, estes fluxos podem ser mutuamente agrupados, no caso da "canopy layer" urbana, através de uma relação de balanço (de radiação/energia) definida pela seguinte expressão:

$$
Q^{*}+Q_{F}=Q_{H}+Q_{E}+\Delta Q_{A}+\Delta Q_{S}+S
$$

Onde, $Q^{*}$ é o balanço radiativo, $Q_{F}$ é o fluxo antropogênico de calor, $Q_{H}$ e $Q_{E}$ são os fluxos turbulentos (convectivos) de calor sensível e latente, respectivamente, $\Delta Q_{A}$ representa a variação advectiva de calor, $\Delta Q_{S}$ a variação do calor armazenado no sistema e $S$ representa processos de remoção de calor (fotossíntese ou escoamento superficial).

Nesse estudo, especial atenção é dada aos fluxos radiativos representados por $Q^{*}$,

Geografia Ensino \& Pesquisa, v. 15, n.1, p. 7-16 jan./abr. 2011

Análise do balanço radiativo na avenida Queiroz Filho - São Paulo/SP sob condição de céu claro na estação seca expressos pela seguinte relação de balanço:

$\mathrm{Q}^{*}=\mathrm{K}^{*}+\mathrm{L}^{*}$

Onde $\mathrm{K}^{*}$ é o balanço radiativo em ondas curtas e $\mathrm{L}^{*} \mathrm{o}$ balanço radiativo em ondas longas.

Finalmente, cabe ressaltar que uma das melhores ferramentas para análise destes fluxos é a realização de transetos móveis contínuos, ou seja, sem interrupção do deslocamento e 
com utilização de um sistema automático contínuo de aquisição de dados. A observação móvel contínua mostra-se como um procedimento capaz de capturar a essência do clima urbano, de modo muito mais eficaz do que qualquer rede de observação fixa (MACHADO, 2009; VOOGT and OKE, 1998).

\section{Caracterização geourbana da Avenida Queiroz Filho}

A área escolhida (em torno das coordenadas $7396.10^{3}$ UTM - lat e $324.10^{3}$ UTM - Ion) para o monitoramento das condições microclimatológicas foi o trecho da Av. Queiroz Filho (Figura 1) limitado entre a Av. Diógenes Ribeiro de Lima e ao cruzamento com a Av. Imperatriz Leopoldina (MACHADO, 2009). $O$ trecho tem aproximadamente 1500 metros de extensão e foi selecionado por reunir uma série de fatores que corroboram para uma melhor compreensão didática do fenômeno a ser estudado. A se ressaltar: disponibilidade de imagem orbital do setor, satisfatório levantamento fotográfico para identificação de elementos da paisagem, possibilidade de se obter observações conjuntas dos fluxos radiativos e das temperaturas das paredes em horários e dias da semana distintos com sensores distintos, particularidade do posicionamento astronômico com o eixo da Avenida ocupando uma direção muito próxima à zonal (oeste-leste), em torno do qual oscila uma trajetória quase perfeitamente senoidal com as faces constituidoras das paredes do "canyon" voltadas para todas as direções possíveis, dentre outros, como a própria variabilidade de tipos de uso da terra (Machado, 2009 e Machado e Azevedo 2008).

O uso da terra oscila entre um arco inicial constituído por empreendimentos comerciais nas duas faces do canyon e poucas árvores, e um arco posterior com face norte bastante recuada, face sul próxima à via e totalmente murada, além de intensamente arborizado, constituída por copas bastante largas.
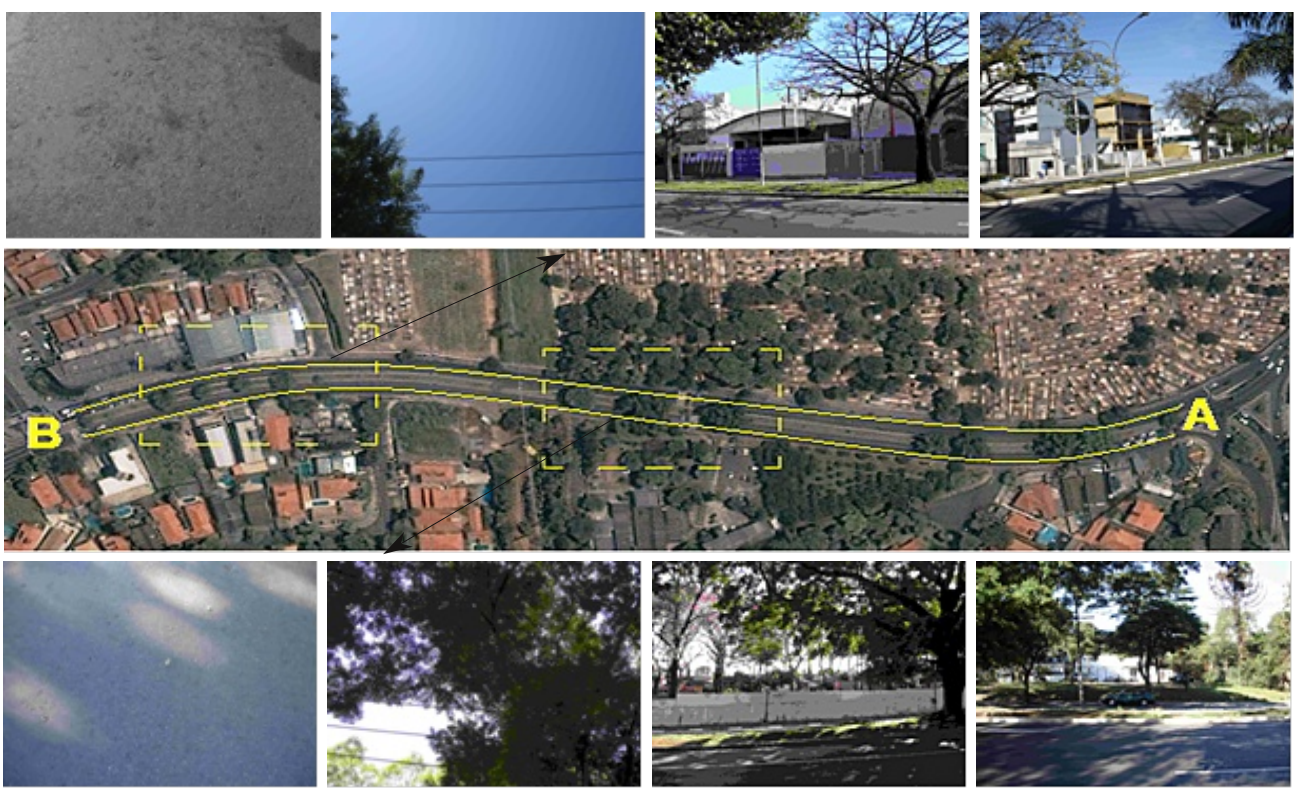

Figura 1: - Imagem SPOT da área em torno à Av. Queiroz Fo. (centro), entre a Av. Diógenes Ribeiro de Lima (A) e a Av. Imperatriz Leopoldina (B). As linhas contínuas representam os trajetos percorridos e correspondem às pistas norte (acima) e sul (abaixo). Os polígonos tracejados delimitam dois setores com ocupações distintas, ao setor oriental correspondem as imagens adjacentes abaixo, enquanto ao setor ocidental correspondem as imagens adjacentes acima. As imagens acima e abaixo também possuem uma correspondência mútua, da esquerda para a direita representam respectivamente a visão do nadir, do zênite, da face sul e da face norte. Fonte: Modificado de Machado (2009). Autor: Machado, A. J. (07/07/2007).

Geografia Ensino \& Pesquisa, v. 15, n.1, p. 7-16, jan./abr. 2011

Antonio Janscke Machado

ISSN 2236- 4994 


\section{Caracterização climática da Avenida Queiroz Filho}

A análise dos fluxos radiativos é interessante, sobretudo, porque desvincula a análise, de uma caracterização preponderantemente estática, quando observado certo padrão de distribuição das temperaturas do ar que preenche a "canopy layer" urbana. Assim se possibilita a inclusão da natureza dinâmica verdadeiramente responsável pela gênese destes padrões de distribuição da temperatura, através da verificação instantânea de setores com diferentes taxas de aquecimento e/ou resfriamento. Aliás, esta possibilidade permite inclusive o reconhecimento da ritimicidade do processo, o que pode viabilizar o prognóstico de padrões de conforto na escala horária, dentro do ciclo diurno ou noturno em uma cidade.

Foram escolhidas a manhã do dia 22 de abril de 2007, um domingo de outono, e a noite do dia 15 de agosto de 2007, uma quarta-feira de inverno. Ambas situações de céu claro, porém, com distintos padrões de umidade relativa do ar. 0 dia 22 foi um dia típico da estação úmida, com ocorrência de pancadas de chuva à tarde, enquanto o dia 15 foi um dia típico da estação seca, com ar poluído e sem evolução de brisa marítima.

$O$ trajeto foi percorrido em ambas situações no sentido $B$ para $A$ (ver Figura 1), através de um suave aclive, pouco mais acentuado ao fim do percurso.

O procedimento metodológico para o monitoramento micrometeorológico no transeto, se fundamenta na utilização de um conjunto de equipamentos (Tabela 1), dispostos sobre uma plataforma móvel (Figura 2), montada na superfície superior de um veículo automotor Ford, modelo Escort.

\footnotetext{
1 Trata-se da camada de coberturas, no caso, de uma cidade. Esta camada extende-se desde um limite inferior definido pelo substrato urbano, até um limite superior definido pela cota média dos topos das edificações. Para maiores detalhes, sobre a dinâmica desta importante camada atmosférica, consultar Oke (1987)
}

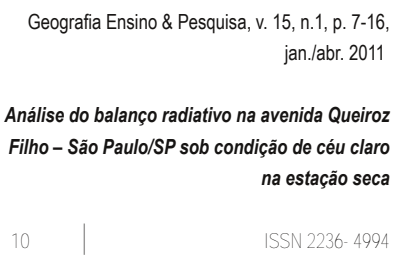

\begin{tabular}{|c|c|c|}
\hline Quantidade & Equipamento & Descrição \\
\hline 1 & $\begin{array}{l}\text { Pirgeômetro Eppley } \\
\text { Laboratory Inc. }\end{array}$ & $\begin{array}{l}\text { Modelo PIR (Infrared Precision), sensível à faixa espectral entre } \\
4,0 \mu \mathrm{m} \text { e } 50,0 \mu \mathrm{m}, \mathrm{n}^{0} \text { de série } 34364 \mathrm{~F} 3 \text {, sensibilidade de } 3,72 \\
\mu \mathrm{V} . \mathrm{W}^{-1} . \mathrm{m}^{-2} \text {, ângulo de visão hemisférica e tempo de resposta de } 02 \\
\text { segundos. }\end{array}$ \\
\hline 1 & $\begin{array}{l}\text { Micrologger Campbell } \\
\text { Scientific Inc. }\end{array}$ & $\begin{array}{l}\text { Modelo CR3000, } \mathrm{n}^{0} \text { de série } 1189 \text {, composto de } 14 \text { canais e } \\
\text { munido de duas baterias ácidas de } 9 \mathrm{~V} \text { cada e recarregáveis. }\end{array}$ \\
\hline 1 & $\begin{array}{l}\text { Saldo-radiômetro Kipp e } \\
\text { Zonen }\end{array}$ & $\begin{array}{l}\text { Modelo NR-LITE, } \mathrm{n}^{0} \text { de série } 052002 \text {, sensibilidade de } 13,6 \mu \mathrm{V} \text {.W } \\
{ }^{1} \cdot \mathrm{m}^{-2} \text {, composto por dois sensores posicionados diametralmente } \\
\text { em oposição, com campo de visão hemisférico para cada um dos } \\
\text { sensores, respectivamente, e uma amplitude de fluxo resultante } \\
\text { esperado entre }-200 \mathrm{~W} \cdot \mathrm{m}^{-2} \text { e } 1500 \mathrm{~W} \cdot \mathrm{m}^{-2} \text {. }\end{array}$ \\
\hline 2 & $\begin{array}{l}\text { Sensores térmicos } \\
\text { infravermelhos Apogee }\end{array}$ & $\begin{array}{l}\text { Modelo IRTS precision, sensíveis à faixa espectral entre } 6,0 \text { um e } \\
14,0 \mu \mathrm{m}, \mathrm{n}^{\circ} \text { de série } 2061 \text { e } 2065 \text {, respectivamente, ângulo de } \\
\text { visão aproximadamente } 20^{\circ} \text { e tempo de resposta inferior a } 1 \\
\text { segundo. }\end{array}$ \\
\hline \multirow[t]{2}{*}{1} & $\begin{array}{l}\text { Sensor de temperatura RM } \\
\text { Young }\end{array}$ & $\begin{array}{l}\text { Modelo RTD, originalmente não calibrados, com } \mathrm{n}^{\circ} \text { de série } \\
\text { S11222 e TS11223, respectivamente, e sensíveis a uma amplitude } \\
\text { térmica de } \pm 50,0^{\circ} \mathrm{C} \text {. }\end{array}$ \\
\hline & $\begin{array}{l}\text { Termopar Camp } \\
\text { bell Scientific Inc. }\end{array}$ & $\begin{array}{l}\text { Modelo Fine Wire, de } 0,003 \text { polegadas, tipo } \mathrm{E} \text { (cobre e } \\
\text { constantan) e } \mathrm{n}^{\circ} \text { de série } 3278 \text {. }\end{array}$ \\
\hline
\end{tabular}

Tabela 1 - Relação de equipamentos utilizados no trabalho de campo. Fonte: Machado (2009). 
O veículo foi utilizado como um laboratório móvel, composto de um suporte metálico para o saldo-radiômetro, instalado na parte dianteira do automóvel, e de uma plataforma instrumental instalada sobre a capota do automóvel.

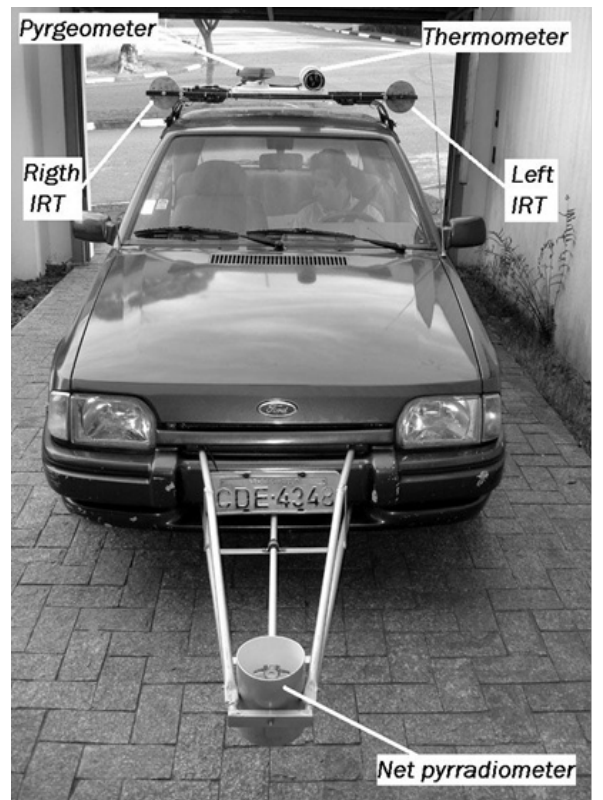

Figura 2 - Laboratório móvel em perspectiva frontal. Na proa do veículo, dispositivo com saldo radiômetro. Acima, plataforma móvel, com termômetro inserido em tubo ventilado (centro, à direita), pirgeômetro com proteção (centro, à esquerda), e polias com termômetros infravermelhos fixos na retaguarda (extremidades laterais, à direita e à esquerda).Fonte: Modificado de Machado (2009).

Autor: Azevedo, T.R. de (26/07/2006).

As medições realizadas com o saldo-radiômetro, de acordo com o recomendado por Machado (2009). Por isso não necessitaram de correções significativas pela presença do anel anti-refratário, pois a limitação do campo de visão do sensor se dá justamente para baixos ângulos, onde a sensibilidade do saldo radiômetro é reduzida. 0 uso deste anel, apesar de constituir uma ligeira limitação ao campo de visão, é necessário aos propósitos do estudo (MACHADO, 2009). Ou seja, limita a influência radiativa e térmica oriunda dos veículos circundantes no trajeto, especialmente nos horários de tráfego intenso. Além disso, inibe a influência do vento frontal, natural ou gerado pelo deslocamento do veículo, sobre o sensor de radiação.

Os percursos realizados com a plataforma foram georreferenciados pela utilização simultânea de um sistema de geoposicionamento manual (GPS Garmin, Modelo 12).

Um termopar foi fixado sobre a superfície interna do anel, para avaliação da temperatura deste e para verificação da possivel influência sobre a componente de ondas longas medida com o saldoradiômetro.

Testes foram preliminarmente realizados visando testar a sensibilidade dos sensores utilizados nesse estudo.

Em relação à resolução espacial, por exemplo, não há possibilidade de um controle exato, pois depende fundamentalmente da velocidade que se pode praticar nas diversas situações encontradas na via. No entanto, podem ser feitas algumas conjecturas. Pelas recomendações propostas por Machado e Azevedo (2005), o veículo deve ser conduzido com uma velocidade em torno de $40 \mathrm{~km} \cdot \mathrm{h}^{-1}$, na faixa direita da via. Em se considerando que, velocidades superiores põem em prejuízo a resolução espacial das observações micrometeorológicas. Em contrapartida, as velocidades inferiores a $40 \mathrm{~km} . \mathrm{h}^{-1}$ podem gerar conflitos e transtornos aos automóveis que circulam ao redor da unidade de monitoramento.

Geografia Ensino \& Pesquisa, v. 15, n.1, p. 7-16, jan./abr. 2011

Antonio Janscke Machado 
Os dados de radiação e temperatura foram ambos amostrados a uma freqüência de 0,5 $\mathrm{Hz}$ e armazenados a uma freqüência de $0,1 \mathrm{~Hz}$.

\section{Resultados}

Na Figura 3 são apresentados e confrontados as componentes do balanço radiativo ( $\left.Q^{*}\right)$ em ondas curtas $\left(K^{*}\right)$ e em ondas longas $\left(L^{*}\right)$ durante uma manhã de domingo de outono, e também numa noite do inverno quando o balanço radiativo $\left(Q^{*}\right)$ coincide com o balanço em ondas longas $\left(L^{*}\right)$. Em contrapartida, na Figura 4 estão representados os padrões de distribuição das temperaturas das paredes do canyon nas duas áreas demarcadas no trajeto entre os trechos B?A da Avenida Queiroz Filho.

Pelo observado na Figura 3, os resultados apresentados, independentemente da estação do ano, apresentam curvas de $L^{*}$ com caracteristicas similares, tanto durante 0 dia (linha contínua abaixo) quanto à noite (linha tracejada abaixo), principalmente no segundo setor do transeto, onde se tem redução da visão do céu devido à coberturas das copas das árvores. No primeiro setor da avenida, no entanto, há uma tendência à divergência entre estas duas curvas da radiação em ondas longas, acarretada pelo afastamento da área arborizada e conseqüente predominância de céu aberto. Note que a linha contínua de $L^{*}$ diurno sobe à esquerda do gráfico, enquanto a linha tracejada de $L^{*}$ noturno desce. Ambas apresentam valores negativos de $L^{*}$, ou seja, a superfície está mais aquecida em relação ao ar. Porém, durante o dia esta diferença é menor, enquanto à noite o gradiente térmico é mais intenso. Em outras palavras, à noite a superfície está resfriando mais rapidamente.

O balanço radiativo diurno é positivo, enquanto o balanço radiativo noturno é negativo, basicamente efeito do aquecimento solar $\left(K^{*}\right)$ no primeiro caso (ver curva no alto da Fig. 3 ). Sendo mais pronunciado no primeiro setor do percurso onde uma visão mais ampla do céu permite $o$ aquecimento superficial.

Considerando apenas 0 balanço em ondas longas $\left(L^{*}\right)$, nota-se similaridade entre a situação diurna e a situação noturna. Sendo a segunda mais pronunciada no sentido negativo para o primeiro setor. A visão mais ampla do céu implica uma maior taxa de resfriamento por perda radiativa.

É curioso notar que, apesar da maior variabilidade média se manifestar nos fluxos $\mathrm{K}^{*} \mathrm{e}$ $\mathrm{Q}^{*}$ (oscilam cerca de $40 \mathrm{~W} \cdot \mathrm{m}^{-2}$ entre o máximo e o mínimo), é no fluxo $\mathrm{L}^{*}$ que se manifesta a maior variabilidade relativa, oscilando cerca de $30 \mathrm{~W} \cdot \mathrm{m}^{-2}$ para a mesma localidade, isto é, quase $80 \%$ da variabilidade média - ver barras de desvio padrão na Figura 3.

Em relação à temperatura das paredes do canyon (Fig. 4), verifica-se em linhas gerais um equilíbrio muito próximo à temperatura do ar, sobretudo, na situação diurna. Na situação noturna as paredes tendem a se tornar ligeiramente mais frias, de um modo geral. Destacando-se, no entanto, o primeiro setor (extremo oeste na Fig. 4) onde as paredes chegam a estar entre 4,0 e $6,0^{\circ} \mathrm{C}$ mais frias do que 0 ar.

Alguns máximos merecem destaque (note os dois picos na Fig. 4, acima). Tanto no

Geografia Ensino \& Pesquisa, v. 15, n.1, p. 7-16 jan./abr. 2011

Análise do balanço radiativo na avenida Queiroz Filho - São Paulo/SP sob condição de céu claro na estação seca extremo oeste como no extremo leste do percurso há presença de paredes, cerca de $12,0^{\circ} \mathrm{C}$ a $6,0^{\circ} \mathrm{C}$ mais aquecidas do que 0 ar. Trata-se da parede de um galpão e do muro de um cemitério dispostos ambos com faces sudeste, e que, portanto, já estão mais expostos há algum tempo a raios solares matutinos. 
Além disso, há também o declínio verificado entre máximos (Fig. 4, abaixo) no segundo setor. Isso se deve fundamentalmente ao pronunciado afastamento relativo da parede do canyon, entreposta ao observador por vários arbustos, árvore e gramíneas.

As amostras de temperatura coletadas podem também ser distribuídas horizontalmente (Fig. 5), fornecendo um panorama interessante da distribuição espacial destas temperaturas.

Nota-se que a temperatura surge realmente como um elemento de homogeneização térmica do ambiente. No caso diurno, observa-se um valor quase uniforme, em torno de $23,0^{\circ} \mathrm{C}$, através do eixo principal da avenida. No caso noturno, percebe-se um padrão semelhante com magnitude em torno de $19,0^{\circ} \mathrm{C}$.

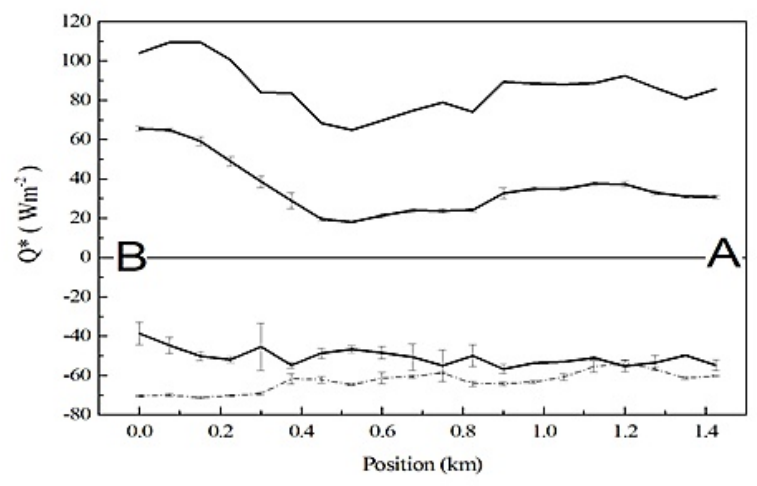

Figura 3 - Distribuição linear do balanço radiativo observado na Av. Queiroz Fo. em torno das 8 h e 15 min de uma manhã de domingo no outono (linha contínua central), e em torno das 21 h e 52 min de uma noite de quarta-feira no inverno (linha tracejada abaixo). As linhas contínuas mais acima e mais abaixo representam, respectivamente, a componente de onda curta estimada para este balanço $\left(K^{*}\right)$ e a componente de onda longa observada para este balanço $\left(L^{*}\right)$.

Fonte: Modificado de Machado (2009).

Org.: Machado, A. J. (2009).

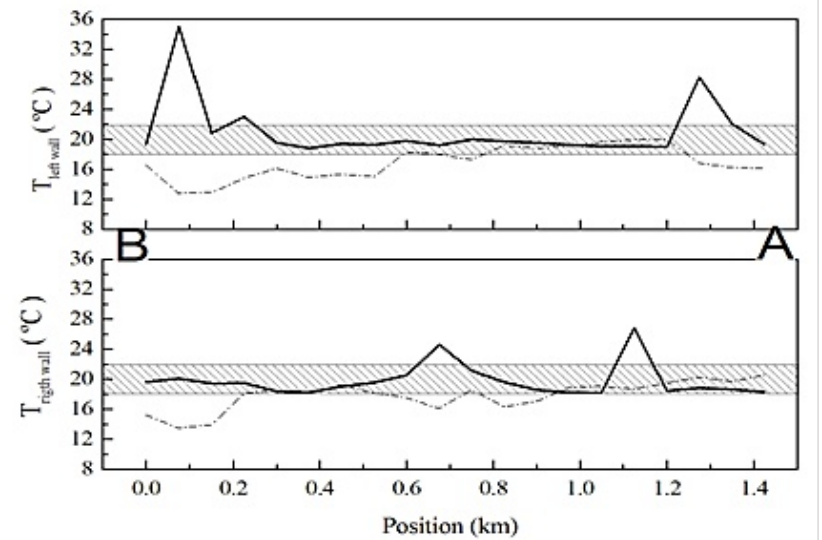

Figura 4 - Distribuição linear da temperatura das paredes observadas na Av. Queiroz Fo. em torno das 8 h e 15 min de uma manhã de domingo no outono (linhas contínuas), e em torno das 21 h e 52 min de uma noite de quarta-feira no inverno (linhas tracejadas). As linhas acima representam as paredes que compõem a face sul, enquanto as linhas abaixo representam as paredes que compõem a face norte. As áreas hachuradas nos gráficos indicam a amplitude da temperatura do ar observada entre as duas situações estudadas.

Fonte: Modificado de Machado (2009).

Org.: Machado, A. J. (2009).

Verifica-se também, como as principais heterogeneidades espaciais encontradas nestas distribuições de temperaturas acentuam-se à medida que nos aproximamos das paredes do canyon.

Os setores mais aquecidos das paredes parecem funcionar como irradiadores térmicos para o ambiente, cuja emanação tende a dissipar-se em um curto espaço até o eixo principal do canyon

Geografia Ensino \& Pesquisa, v. 15, n.1, p. 7-16, an./abr. 2011

Antonio Janscke Machado 
urbano, através do meio aéreo que o preenche. Este aspecto ressalta o fato de como o meio atmosférico é fundamentalmente aquecido pela atividade convectiva iniciada a partir das superfícies que compõem este meio.

Ainda vale ressaltar a presença dos intensos gradientes térmicos horizontais, que se manifestam durante o dia na porção ocidental e extremo oriental da avenida, e à noite, sobretudo, na porção ocidental. Enquanto na área centro oriental da avenida prevalece um gradiente mais suave e homogêneo, sendo praticamente nulo neste setor, para o caso noturno.

Este padrão encontrado, para os gradientes térmicos, parece estar fortemente relacionado com os padrões de distribuição encontrados para $Q^{*}$.

$O$ setor da Avenida com gradientes térmicos mais intensos (Figura 5 à esquerda) é aquele que corresponde tanto à maior intensidade observada para o fluxo $Q^{*}$, quanto à maior intensidade de $L^{*}$. Ou seja, é aquele setor que experimenta o maior aquecimento diurno, bem como o maior resfriamento noturno (Fig. 3).

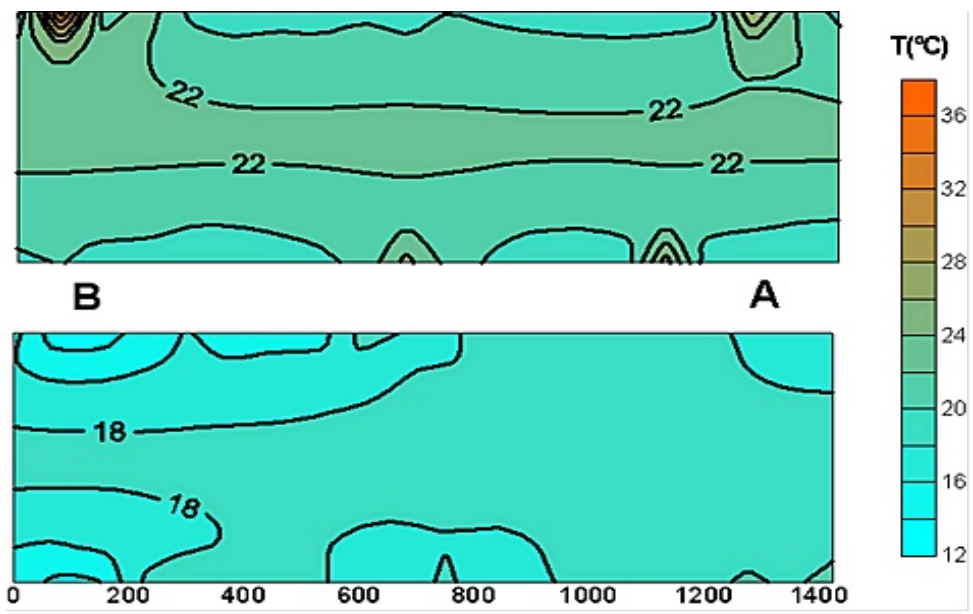

Figura 5 - Distribuição espacial das temperaturas superficiais das paredes e do ar, interpoladas no plano correspondente à cota da plataforma móvel (Fig. 1), a partir das observações realizadas na Av. Queiroz Fo. (Fig. 4), entre os pontos B e A representados na Fig. 2, em torno das 8 h e 15 min de uma manhã de domingo no outono (acima), e em torno das 21 h e 52 min de uma noite de quarta-feira no inverno (abaixo).

Fonte: Trabalho de campo (2007)

Org.: Machado, A. J. (2010).

Geografia Ensino \& Pesquisa, v. 15, n.1, p. 7-16 jan./abr. 2011

Análise do balanço radiativo na avenida Queiroz Filho - São Paulo/SP sob condição de céu claro na estação seca

\section{Considerações Finais}

Os padrões de distribuição do fluxo radiativo e da temperatura superficial observados evidenciam o importante papel da vegetação em atenuar a variabilidade diurna e noturna da perda radiativa superficial. Sobretudo, em reduzir o resfriamnto superficial noturno. De fato, como outros autores observam (RICHARDS and OKE, 2002) a cobertura arbórea nas cidades tem este efeito e pode implicar na formação de hidrometeoros superficiais, tais como orvalho e geada.

As medições móveis contínuas mostram-se extremamente úteis ao se tratar de uma análise topoescalar. De fato, é evidente o reconhecimento de uma variabilidade dos padrões, relacionada à modificação do tipo de uso da terra, através de diferentes setores do trajeto estudado. Mediante as condições de deslocamento do veículo, verifica-se que uma resolução espacial em torno de $100 \mathrm{~m}$ é característica da variação dos padrões neste tipo de experimento móvel. Para análises microescalares, no entanto, quando se necessite de uma maior resolução espacial, da ordem de 10 m ou menos, as medições fixas ainda são recomendáveis. 
Mesmo sob distintas condições de umidade disponível no ar, poluição atmosférica e atividade urbana, os padrões de distribuição do balanço radiativo observado indicam que, sob condições de céu aberto, com pouca ou sem nebulosidade, a variabilidade temporal da perda radiativa em ondas longas é atenuada em áreas mais arborizadas. Ou seja, a presença de densa cobertura arbórea em uma área urbana pode atenuar drasticamente a variabilidade térmica. Enquanto para um setor com pouca ou sem vegetação a taxa de resfriamento radiativo oscila entre $40 \mathrm{e} 80 \mathrm{~W} \cdot \mathrm{m}^{-2}$, durante o período diurno e o período noturno, respectivamente, para outro setor, densamente arborizado, esta mesma taxa de resfriamento permanece aproximadamente constante, em torno de $60 \mathrm{~W} . \mathrm{m}^{-2}$, independentemente do ciclo diurno e noturno.

Esta pesquisa também constata que nos setores menos arborizados, ocorre o padrão térmico tradicional nas paredes do canyon urbano, que resulta numa condição típica de transferência do fluxo de calor sensível entre estas superfícies e a atmosfera urbana. Mas, no entanto, nestes mesmos setores, durante uma noite com céu aberto, verifica-se que estas paredes podem estar significativamente mais resfriadas do que 0 ar. Percebe-se a ocorrência de amplitudes térmicas máximas negativas entre 0 ar e as paredes, de até $6,0^{\circ} \mathrm{C}$ de magnitude. Esta amplitude negativa propicia a ocorrência atípica de transferência de calor sensível da atmosfera para a superfície, o que também contribui para o seu resfriamento sob tais condições.

\section{Agradecimento}

À Fundação de Amparo à Pesquisa do Estado de São Paulo (FAPESP), processo $n^{0}$ 05/56287-0.

\section{Referências Bibliográficas}

BORGES, C.F; DUMMER, J. e OESTER, E. O clima urbano na cidade de Pelotas, RS, in: CONGRESSO DE INICIAÇÃO CIENTÍFICA, 17 e CONGRESSO DE PÓS-GRADUAÇÃO EM GEOGRAFIA, 10, 2008. Pelotas, Anais do XVII Congresso de Iniciação Científica e X Congresso de Pós-graduação em Geografia, Rio Grande do Sul, UFPel, 2008, cd-rom.

COSTA, Eduíno Rodrigues da; SARTORI, Maria da Graça Barros; FANTINI, Vanessa. Análise do conforto térmico do Parque Itaimbé - Santa Maria/RS sob condições atmosféricas de domínio da massa polar velha em situação sazonal de primavera. Geografia: Ensino \& Pesquisa, Santa Maria, v. 14, n.2, p. 16 - 26, 2010.

MACHADO, Antonio Jaschke. Distribuição espacial do fluxo radiativo em ondas longas na Região Metropolitana de São Paulo. 2009. 273f. Tese (Doutorado em Geografia Física) - Departamento de Geografia - Faculdade de Filosofia, Letras e Ciências Humanas, USP, São Paulo.

Tarik Rezende de. A divergência radiativa na camada próxima ao chão, in: SIMPósıo BRASILEIRO DE CLIMATOLOGIA GEOGRÁFICA, 8, 2008. Alto Caparaó, Anais do VIII Simpósio Brasileiro de Climatologia Geográfica, Minas Gerais, UFU, 2008, cd-rom.

Parametrização da emissão termoradiativa aplicada à análise do conforto urbano, GEOUSP: Teoria \& Prática, São Paulo, vol. 19, p. 179 - 198, 2006.

Fluxo diurno de radiação de onda longa recebida em um trajeto urbano arborizado, in: SIMPÓSIO BRSILEIRO DE GEOGRAFIA FÍSICA APLICADA, 11, 2005. São Paulo, Anais do XI Simpósio Brasileiro de Geografia Física Aplicada, São Paulo, USP, 2005, cd-rom.

OKE, Timothe R. Boundary Layer Climates. London: Routledge, 2nd ed, 1987. 435p.

OLGYAY, V. Arquitectura y clima - manual de diseño bioclimático para arquitectos y urbanistas. Barcelona, Editorial Gustavo Gili, SA, 5a tirade, 2008.

Geografia Ensino \& Pesquisa, v. 15, n.1, p. 7-16, jan./abr. 2011

Antonio Janscke Machado

ISSN 2236- 4994 
RICHARDS, K. and OKE, T. R. Validation and results on a scale model of dew deposition in urban environments. International Journal of Climatology, 22, p.1915-1933, 2002.

VOOGT, J. A. and OKE, T. R. Radiometric temperatures of urban canyon walls obtained from vehicle traverses. Theoretical and Applied Climatology, 60, p. 199-217, 1998.

\section{Correspondência}

Antonio Jaschke Machado - Faculdade de Ciências e Tecnologia - UNESP. Departamento de Geografia, sala 3. Rua Roberto Simonsen, 305 CEP 19060-900 Presidente Prudente SP.

E- mail: jaschke.machado@fct.unesp.br

Recebido em 07 de julho de 2010.

Revisado pelo autor em 15 de fevereiro de 2011

Aprovado em 12 de março de 2011

Análise do balanço radiativo na avenida Queiroz Filho - São Paulo/SP sob condição de céu claro na estação seca 